\title{
Induction for senior house officers. Part I: The hospital programme
}

\author{
Simon J Ward, Paula Stanley
}

\begin{abstract}
Summary
The study was set up to examine how an induction programme can be designed to meet the needs and expectations of senior house officers (SHOs) beginning a new post in a hospital. A total of $63 \mathrm{SHOs,} \mathrm{in}$ five hospitals in the Anglia region, participated in standardised structured interviews up to 3 months after starting their post, by sorting a list of 38 possible induction topics in order of priority. Trainees' early induction needs were found to centre on day-one service activities, ie, information that enables them to undertake their service work efficiently and effectively, is particularly valued and required early. Information related to clinical education and training is also valued, but many trainees prefer it to be provided after they have been in post for a week or two. Much induction information can also be effectively conveyed in writing, with little or no need for additional formal presentation. We conclude that first-day induction programmes which strive to satisfy the range of trainee needs in one session fail to take account of the different priorities that trainees attach to induction information. Trainees do not want all information at once. Information of prime concern to clinical tutors, namely education, training and generic skills, is generally favoured after a week or two. To ensure that trainees' hospital induction needs are met in an efficient and effective way, programmes must be flexible and timely, and supported by comprehensive written information.
\end{abstract}

Keywords: induction; training; education

Hospital induction programmes integrate trainees into hospitals as quickly as possible, aiding smooth running, and reduce levels of anxiety, allowing trainees to feel more competent more quickly. ${ }^{1}$ Induction programmes are strongly recommended in a number of reports and by postgraduate deans. ${ }^{2-7}$ Indeed, they are now mandatory for pre-registration house officers. $^{8}$

Although most hospitals now run an induction programme, there is great variety in their content and style. ${ }^{3}$ This may be due to different published lists of suggested topics ${ }^{5}$ or to lack of systematic research in this area. Most programmes are chosen by seniors, rather than by trainees as advocated, ${ }^{19}$ consequently, they may not meet the needs of trainees. Programmes often consist of short didactic presentations, ${ }^{13}$ which may not be the optimal adult learning method. ${ }^{10}$ Also, trainees may have a diverse range of experience, giving rise to different needs and expectations, which may or may not be fulfilled by an induction programme. This programme may be repeated regularly in the same format, irrespective of changing needs, whilst the programme's usefulness is rarely evaluated. ${ }^{3}$ Special induction problems also exist for trainees who are not synchronised with the main rotation times, and for other European and foreign graduates.

Published research discusses induction for pre-registration house officers ${ }^{13}$ or examines mixed grades of trainees. ${ }^{11}$ It does not concentrate on the 'lost and breeding tribe' of senior house officers (SHOs). ${ }^{12}{ }^{13}$ This research takes SHOs as its focus. It examines how an induction programme may be designed to maximise the chances that it meets the diverse range of trainees' needs and expectations.

\section{Methods}

A total of 115 SHOs starting a post in August 1996 or February 1997, in one of five training hospitals in the Anglia region, were invited to contribute to the study. There was a 55\% response rate. Each $\mathrm{SHO}$ sorted 38 induction topics, collated from the literature, ${ }^{1-8}$ in response to three questions:

Question 1: How valuable would each topic be to you if covered on an induction programme when joining a new hospital (of real value / of little value)?

Question 2: At what stage of your post would these topics best be provided (within the first few days / after a week or two)?

Question 3: In what form would the information be most appropriately conveyed (in writing only / in writing supported by spoken information) and in what style (formal presentation / group discussion / practical activity)?

The data were analysed using Microsoft SPSS. Frequency counts were performed and Chi-Square and Mann-Whitney-U tests for non-parametric data employed.

\section{Results}

Sixty-three SHOs from 10 specialties were interviewed. Most (75\%) of the trainees were in their first SHO post in the hospital and $25 \%$ were in the first SHO post of their career. 
Table 1 Responses $(n=63)$ to the question "how valuable would each topic be to you if covered on an induction programme when joining a new hospital?"

\begin{tabular}{|c|c|c|c|}
\hline Title & Real value (\%) & Little value (\%) & Unsure of value (\%) \\
\hline Ordering tests/investigations & 89 & 8 & 3 \\
\hline Cardiopulmonary resuscitation & 88 & 8 & 3 \\
\hline Study leave allowance & 87 & 8 & 5 \\
\hline Education events/timetable & 87 & 10 & 3 \\
\hline Service departments/pathology, etc & 86 & 11 & 3 \\
\hline Bleeps/switchboard & 85 & 14 & 1 \\
\hline Identification of educational supervisor & 79 & 21 & 0 \\
\hline Acute/A \& E admissions & 79 & 16 & 5 \\
\hline Photo ID/badge & 74 & 15 & 11 \\
\hline Pharmacy/tablets to take away & 74 & 20 & 7 \\
\hline Discharge procedures ${ }^{\star}$ & 72 & 29 & 0 \\
\hline Death certificates \& coroner & 69 & 29 & 2 \\
\hline Contract, terms \& conditions & 68 & 24 & 8 \\
\hline Meet clinical tutor & 68 & 24 & 8 \\
\hline Car parking/permit & 66 & 29 & 5 \\
\hline Careers advice & 65 & 31 & 5 \\
\hline Dining facilities/out of hours catering & 64 & 26 & 10 \\
\hline Tour of educational facilities & 64 & 23 & 13 \\
\hline Hospital computer system & 64 & 25 & 11 \\
\hline Sick leave/cover & 64 & 24 & 7 \\
\hline P45, salary/wages & 63 & 27 & 10 \\
\hline Keys/rooms/housekeeping & 61 & 29 & 10 \\
\hline How $\&$ when to transfer patients & 61 & 24 & 15 \\
\hline Paramedical support staff & 59 & 34 & 7 \\
\hline Mess/tour of facilities & 58 & 36 & 6 \\
\hline Communicating with GPs & 57 & 37 & 6 \\
\hline Hospital forms/notes & 56 & 33 & 11 \\
\hline Department/facilities & 56 & 31 & 13 \\
\hline Local amenities ${ }^{\star}$ & 55 & 31 & 14 \\
\hline BMA/GMC indemnity & 53 & 32 & 15 \\
\hline Hospital tour & 52 & 36 & 12 \\
\hline Ethical issues/consent ${ }^{\star}$ & 45 & 45 & 10 \\
\hline Training policy/strategy (ns) & 44 & 37 & 19 \\
\hline Health \& safety/fire drill` & 38 & 52 & 10 \\
\hline Bereavement/breaking bad news & 38 & 55 & 7 \\
\hline Laundry/white coats & 37 & 55 & 8 \\
\hline Independent/pastoral advice ${ }^{\star}$ & 28 & 59 & 13 \\
\hline Chief executive's welcome & 18 & 68 & 14 \\
\hline
\end{tabular}

Chi-Square: all topics significant at $\mathrm{p}<0.01$ except ${ }^{\star} \mathrm{p}<0.05 \& \mathrm{~ns}=$ non-significant (see text for explanation)

Table 2 Responses $(n=63)$ to the question "at what stage of the post would these topics be best provided?"

\begin{tabular}{|c|c|c|c|}
\hline Title & $\begin{array}{l}\text { Within first } \\
\text { week }(\%)\end{array}$ & $\begin{array}{l}\text { After a week or } \\
\text { two }(\%)\end{array}$ & $\begin{array}{l}\text { No strong } \\
\text { views (\%) }\end{array}$ \\
\hline Bleeps/switchboard & 93 & 2 & 5 \\
\hline Keys/rooms/housekeeping & 92 & 3 & 5 \\
\hline Ordering tests/investigations & 92 & 5 & 3 \\
\hline Acute/A \& E admissions & 85 & 10 & 5 \\
\hline Photo ID/badge & 85 & 10 & 5 \\
\hline Hospital tour & 84 & 5 & 11 \\
\hline Service departments/pathology, etc & 82 & 15 & 4 \\
\hline Dining facilities/out of hours catering & 79 & 8 & 13 \\
\hline Mess/tour of facilities & 79 & 7 & 15 \\
\hline Car parking/permit & 77 & 11 & 11 \\
\hline Hospital forms/notes & 76 & 6 & 18 \\
\hline Pharmacy/tablets to take away & 76 & 19 & 5 \\
\hline Department/facilities & 73 & 18 & 10 \\
\hline How \& when to transfer patients & 72 & 21 & 7 \\
\hline Contract, terms \& conditions & 69 & 26 & 5 \\
\hline Cardiopulmonary resuscitation & 68 & 27 & 5 \\
\hline Hospital computer system & 66 & 21 & 13 \\
\hline Discharge procedures & 66 & 31 & 4 \\
\hline Laundry/white coats & 64 & 15 & 21 \\
\hline $\mathrm{P} 45$, salary/wages & 60 & 34 & 6 \\
\hline Death certificates \& coroner & 57 & 37 & 6 \\
\hline Tour of educational facilities & 55 & 35 & 10 \\
\hline Education events/timetable & 53 & 43 & 4 \\
\hline Paramedical support staff & 52 & 24 & 24 \\
\hline Identification of educational supervisor & 48 & 40 & 11 \\
\hline Communicating with GPs (ns) & 46 & 31 & 23 \\
\hline BMA/GMC indemnity (ns) & 40 & 37 & 23 \\
\hline Study leave allowance & 37 & 56 & 7 \\
\hline Chief executive's welcome & 36 & 8 & 56 \\
\hline Health \& safety/fire drill (ns) & 34 & 28 & 38 \\
\hline Meet clinical tutor $\star$ & 33 & 49 & 18 \\
\hline Sick leave/cover & 31 & 59 & 10 \\
\hline Training policy/strategy (ns) & 29 & 45 & 26 \\
\hline Local amenities (ns) & 28 & 48 & 24 \\
\hline Ethical issues/consent (ns) & 28 & 41 & 31 \\
\hline Bereavement/breaking bad news (ns) & 21 & 41 & 38 \\
\hline Independent/pastoral advice (ns) & 12 & 45 & 41 \\
\hline Careers advice & 3 & 71 & 26 \\
\hline
\end{tabular}

Chi-Square: all topics significant at $\mathrm{p}<0.01$ except ${ }^{\star} \mathrm{p}<0.05 \& \mathrm{~ns}=$ non-significant (see text for explanation)
Trainees were first questioned about the value of programme topics and their responses are detailed in table 1 . Thirty-one of the 38 topics $(82 \%)$ were rated 'of real value' by more than half the sample and only five $(13 \%)$ were rated 'of little value' by more than half the sample (health and safety/fire drill, bereavement/ breaking bad news, laundry/white coats, independent/pastoral advice, chief executive's welcome), reflecting the breadth of topics upon which programmes could valuably comment. For every topic, at least $10 \%$ of trainees gave a rating other than 'of real value', suggesting that whatever information is provided, it will be of little value to at least a small proportion of trainees. Topics to which fewer trainees attributed real value included those which contribute little to trainees' immediate concerns about how to function successfully in their new post. No single programme will meet the needs of all trainees, therefore ways must be found of minimising the provision of unnecessary information.

Statistically significant differences in value ratings between samples were found in relation to a small number of topics. Trainees who had worked in the hospital before assigned more value to careers advice $(\mathrm{p}<0.01), \mathrm{P} 45 /$ salaries and wages $(p<0.05)$, and educational activities/ timetable $(p<0.05)$ than those who had not. Trainees in their second or subsequent SHO post were more likely to value information on housekeeping/accommodation $\quad(p<0.01)$, laundry/white coats $(\mathrm{p}<0.05)$, car parking/ permit $(\mathrm{p}<0.05)$. Those in their first SHO post were more likely to value meeting the clinical tutor $(p<0.05)$ and information on independent pastoral advice $(\mathrm{p}<0.05)$.

Although the number of topics that show significant differences between groups are small, these findings suggest differing needs among SHOs. Consequently, programmes need to be sufficiently flexible to allow trainees to select appropriate information.

Trainees were then questioned about programme timing and their responses are detailed in table 2. More than half the sample suggested that two out of three topics $(63 \%)$ would be best provided within the first week and more than half suggested that three of the 38 topics $(8 \%)$ would best be provided at a latter stage (study leave, sick leave/cover and careers advice). The high proportion of trainees who had no strong views about the timing lends support to the view that there are topics that are not essential to provide during the first week, and could be appropriately provided later.

Topics which more trainees considered were best provided early, or about which they had no strong views, grouped around three themes: orientation: tour of hospital, mess/facilities and educational facilities; timetable of educational activities and events; administrative and 'comfort' requirements: bleeps/switchboard; keys/ rooms/housekeeping; photo ID/badge; dining facilities/out-of-hours catering; car-parking and permit; contract terms and conditions; laundry/white coats; P45/salaries/wages; essential knowledge and skills to practise from day one: 
Table 3 Responses $(n=63)$ to the question "in what form would the information be most appropriately conveyed and in what style?"

\begin{tabular}{|c|c|c|c|c|c|}
\hline Title & Written only (\%) & $\begin{array}{l}\text { Written \& formal } \\
\text { presentation (\%) }\end{array}$ & $\begin{array}{l}\text { Written \& practical } \\
\text { activity (\%) }\end{array}$ & $\begin{array}{l}\text { Written E group } \\
\text { discussion }(\%)\end{array}$ & Unsure (\%) \\
\hline Car parking/permit & 86 & 8 & 3 & 3 & 0 \\
\hline Dining facilities/out of hours catering & 85 & 10 & 2 & 0 & 3 \\
\hline Local amenities & 83 & 3 & 3 & 0 & 10 \\
\hline Bleeps/switchboard & 80 & 13 & 7 & 0 & 0 \\
\hline Keys/rooms/housekeeping & 80 & 11 & 8 & 0 & 0 \\
\hline Sick leave/cover & 79 & 17 & 3 & 0 & 0 \\
\hline P45, salary/wages & 74 & 23 & 2 & 0 & 2 \\
\hline BMA/GMC indemnity & 73 & 13 & 2 & 6 & 6 \\
\hline Discharge procedures ${ }^{\star}$ & 71 & 29 & 0 & 0 & 0 \\
\hline Contract, terms \& conditions & 70 & 19 & 0 & 10 & 2 \\
\hline Education events/timetable & 70 & 19 & 3 & 9 & 0 \\
\hline Study leave allowance & 67 & 23 & 2 & 8 & 0 \\
\hline Paramedical support staff & 64 & 28 & 0 & 4 & 4 \\
\hline Training policy/strategy & 64 & 20 & 2 & 10 & 5 \\
\hline Hospital forms/notes & 60 & 21 & 10 & 3 & 7 \\
\hline Death certificates \& coroner & 58 & 24 & 2 & 15 & 2 \\
\hline Pharmacy/tablets to take away & 56 & 34 & 3 & 7 & 0 \\
\hline Service departments/pathology, etc & 50 & 39 & 3 & 8 & 0 \\
\hline Ordering tests/investigations & 50 & 36 & 8 & 6 & 0 \\
\hline How \& when to transfer patients & 49 & 24 & 5 & 14 & 7 \\
\hline Ethical issues/consent & 48 & 17 & 3 & 31 & 0 \\
\hline Acute/A \& E admissions & 44 & 38 & 7 & 7 & 5 \\
\hline Communicating with GPs & 41 & 25 & 3 & 26 & 5 \\
\hline Bereavement/breaking bad news & 38 & 3 & 10 & 45 & 4 \\
\hline Hospital computer system & 31 & 8 & 49 & 5 & 7 \\
\hline Cardiopulmonary resuscitation & 2 & 5 & 92 & 1 & 1 \\
\hline
\end{tabular}

Chi-Square: all topics significant at $\mathrm{p}<0.01$ except ${ }^{\star} \mathrm{p}<0.05$ (see text for explanation)

ordering tests/investigations; acute/emergency admissions procedures; service departments; hospital forms/notes; pharmacy/tablets to take away; departments and facilities; how/when to transfer patients; cardiopulmonary resuscitation (CPR); hospital computer system; discharge procedures; death certificates/coroner; paramedical support staff.

Topics that a greater proportion of trainees favoured being provided after a week or two, or about which they had no strong views about their timing, grouped around three themes: education and training: identification of educational supervisor; meeting the clinical tutor; study leave arrangements; statement of training policy/practice; career advice; generic skills: communicating with GPs; ethical issues/ consent; bereavement/breaking bad news; hospital administrative requirements: BMA/GMC indemnity certificates; health and safety/fire drill; sick leave arrangements/cover.

The findings suggest that induction should not be thought of as a one-off first-day event, but rather as a staged programme continuing into the post. Those topics of primary concern to clinical tutors, namely education, training and generic skills, appear to be candidates for provision, not on the first day as often happens, but at a time when trainees have settled into their posts and can turn their attention from the immediate pressures of service to wider professional development issues.

Three topics which a greater proportion of trainees favoured being provided after a week or two fell outside these themes: chief executive's welcome; sources of independent/ pastoral advice and information of local amenities.

There were some significant differences $(p<0.05)$ on some variables, according to whether or not the trainee had worked in the hospital before and whether or not the trainee was in his or her first SHO post. Trainees new to the hospital were more likely to want the chief executive's welcome, information about study leave, laundry/white coats and local amenities earlier than those who were not. This provides further support for the need for induction programmes to be flexible, allowing trainees to select the topics about which they wish to receive information.

Finally, trainees were questioned about programme formats and their responses are detailed in table 3. Trainees sorted 26 of the

Table 4 A model of a staged approach to induction

\begin{tabular}{|c|c|c|}
\hline Stage & One & Two \\
\hline Title & An introduction to service & An introduction to clinical education $\&$ training \\
\hline Aim & $\begin{array}{l}\text { To equip trainees with the information } \& \text { resources to deliver } \\
\text { service from day one }\end{array}$ & $\begin{array}{l}\text { To equip trainees with the knowledge \& skills to maximise teaching \& learning } \\
\text { opportunities (formal and informal) }\end{array}$ \\
\hline \multirow[t]{2}{*}{ Content } & Hospital-wide services/information & $\begin{array}{l}\text { Hospital-wide approach to education \& training and advice on how to create and } \\
\text { use teaching \& learning opportunities (formal and informal) }\end{array}$ \\
\hline & Departmental services/information & $\begin{array}{l}\text { Departmental expectations, what trainees can expect to receive } \& \text { what is expected } \\
\text { of trainees. Planning career/role development }\end{array}$ \\
\hline \multirow[t]{3}{*}{ Format } & Written advice on all induction topics (service \& training) & Written advice on educational events, study leave processes \\
\hline & $\begin{array}{l}\text { Formal presentations where necessary on service issues only, } \\
\text { to support written materials }\end{array}$ & $\begin{array}{l}\text { Group discussions with Clinical Tutor on how to get the most out of training } \\
\text { opportunities }\end{array}$ \\
\hline & Practical activity on eg, CPR, use of computer system & Formal meeting with educational supervisor/clinical tutor/careers counsellor \\
\hline
\end{tabular}


original 38 topics (excluding those which could only be provided in one format, eg, a tour) according to the format which they considered the best. On only seven topics $(27 \%)$ did more than half the sample suggest that presentation in addition to written form was required. Topics particularly amenable to group discussion included the generic skill topics of ethics/ consent; communicating with GPs, and bereavement/breaking bad news. Those particularly amenable to practical activity included CPR and use of the hospital computer system.

Trainees who had worked in the hospital previously, as compared to those who had not, were more likely to want information presented to them orally as well as in writing in relation to: the hospital computer system $(\mathrm{p}<0.01)$ and paramedical support staff $(\mathrm{p}<0.05)$. This was also the case for trainees in their first SHO job as compared to those who were not, in relation to: a statement of training policy/practice $(p<0.05)$, and how and when to transfer patients $(p<0.05)$. Trainees in their second or subsequent SHO post were more likely to want information presented orally as well as in writing on: CPR $(\mathrm{p}<0.05)$; keys/rooms/ housekeeping $(\mathrm{p}<0.05)$, and the hospital computer system $(\mathrm{p}<0.05)$.

Thus, although trainees value information on a wide range of topics, much can be conveyed in writing. This written form has the advantage of being available as a reference source to be used as required and also allows the selection of information according to need, rather than requiring trainees to filter out irrelevant information as it is presented.

\section{Discussion}

How can hospital induction be improved? On the basis of these findings, a two-stage approach to induction is proposed (see table 4). This approach would reduce disruption to service during the induction period and place fewer demands upon trainees at a time of great anxiety, allowing them to absorb information over time. This model integrates hospital induction with departmental induction, so providing a coordinated approach. Departmental induction is the subject of an ensuing article.

Stage one, on day one, provides essential service information. Stage two, provided after a week or two, focuses on education and training. The practical problem of getting SHOs together for stage two can be minimised by using established lunch-time education slots which trainees would ordinarily attend. Generic skills training, ${ }^{5}$ where required, could flow from stage two sessions.

From the findings of this study a number of 'take-home' practical guidelines can be suggested when organising hospital induction programmes (box). Induction programme organisers are faced with an increasing variety of suggestions and standards concerning information that may be appropriate for programmes to contain, eg, health and safety regulations. In addition, stakeholders other than the trainees, such as the coroner's officer,

\section{Practical guidelines for organising a} hospital induction

- leave little to chance by providing comprehensive information and advice

- use written as well as oral advice to provide a reference resource

- comprehensive written advice ensures its availability to trainees not synchronised with the main rotation times

- use a staged approach that addresses trainees' basic 'comfort' requirements as early as possible

- provide information on education, training and generic skills later

- vary the presentation of information by using practical activities and restricting formal, oral presentations to essential information only

- remain conscious of trainees' different needs and structure the programme accordingly, eg, ask trainees who have worked in the hospital before to arrive after the tour

- monitor, evaluate and adapt the programme to meet changing needs over time

infection control and fire officers, may well have differing views on the optimal programme content, timing or format. Thus it is important for organisers to note that some topics may be vital to provide, despite trainees attaching less value to them. At the same time, organisers face conflicting time constraints between service commitments and education requirements. Consequently, all of these factors have to be placed into the institutional contexts in which programmes take place. Variations between induction programmes are therefore inevitable because compromises will be necessary. To facilitate these compromises, collaboration and partnerships will be needed and this is especially important between trainee and trainer, eg, as learning contracts. Objective, as well as subjective, evaluations of the programmes and their value and effectiveness in 'real-life' clinical contexts, using validated outcome measures, is also essential. Well planned and efficient hospital induction may then allow enhanced trainee performance and maximise the quality of patient care provided.

\section{Conclusion}

Hospital induction programmes are important and highly valued. Programmes often consist of one-off, first day collections of didactic presentations which may not meet the diverse range of needs that trainees have, nor their preferences for style of presentation or timing. Flexible, timely programmes, supported by comprehensive written information, are needed. This research has led to the construction of a two-stage model for induction, based on the sound educational principle of assessing trainees' needs. Stage one focuses upon trainee capability to undertake service work and to respond to emergencies from day one. Once trainees feel in control of the service responsibilities, stage two focuses upon clinical education and training. An effective induction programme does much to smooth the process 
of assimilation of new information. Where hospitals provide sound, well-designed and timely induction programmes, trainees receive the information they need, at a time when they need it, and in a format that makes the process valuable and interesting. Such programmes remove much of trainees' initial anxieties enabling them to move quickly and comfort-

1 Gale R, Jackson G, Nicholls $M$, How to run an induction meeting for house officers. BMF 1992;304:1619-20.

2 Committee of Postgraduate Medical Deans and the UK Conference of Postgraduate Deans. SHO training: tackling the issues, raising the standards. Discussion paper. London, January 1995.

3 Standing Committee on Postgraduate Medical and dental Education (SCOPME). A good start. A report on job induction for hospital doctors and dentists in training. London: SCOPME, 1993.

4 General Medical Council. Recommendations on general clinical training. London: General Medical Council, 1992.

5 Royal College of Physicians. A core curriculum for Senio House Officers in general (internal) medicine and the medical specialities, 2nd edn. Royal College of Physicians of London, 1997 6 Royal College of Physicians. General professional training. The
Royal College of Physicians guide for trainees and trainers. Royal College of Physicians of London, 1995. ably into making an effective contribution to service and to profiting from training provided.

We acknowledge Professor DH Hargreaves for his advice and guidance and Dr JS Biggs for his support.

This research was funded by the Anglia Postgraduate Medical and Dental Education Committee as part of the Project on the Training of Doctors in Hospital, University of Cambridge.

7 British Medical Association Junior Doctors Committee. Funior doctors- the new deal. London: British Medical Association, 1991.

8 General Medical Council. The new doctor. London: General Medical Council, 1997.

9 Salter R. The US residency programme - lessons for pre-registration house officer education in the UK? Postgrad Med f 1995;71:273-7.

10 Knowles MS. The adult learner: a neglected species. Houston, TX: Gulf Publishing, 1978.

11 Willaims JG, Cheung WY. Induction training, career counselling, and performance review: views of junior medical staff. Postgrad Med F 1998;74:411-5.

12 Dillner L. Senior house officers: the lost tribes. BMF 1993; 307:1549-51.

13 Harris E, Ferreira P. Training senior house officers. BMf 1997;314:692-3. 